\title{
Retinomotor Movement of All Spectral Cone Types of Red Sea Bream Pagrus major in Response to Monochromatic Stimuli and UV Sensitivity*1
}

\author{
Gunzo Kawamura, Mikayo Miyagi, and Kazuhiko Anraku \\ Faculty of Fisheries, Kagoshima University, Shimoarata, Kagoshima 890, Japan \\ (Received June 7, 1996)
}

This paper examines the hypothesis that spectral cone types exhibit different retinomotor movements in response to monochromatic radiation and can thus be identified histologically in the retina. Red sea bream Pagrus major, 79-105 $\mathrm{mm}$ in total length, were dark adapted in a glass aquarium, then exposed overhead to various intensities of white light and monochromatic stimuli with peaks at 337, $368,466,551$ and $609 \mathrm{~nm}$. The retinae from fish from each stimulus were examined histologically and scored for thickness of the cone layer and the pigment layer relative to the total retinal thickness. The red sea bream tested showed retinomotor response to $368 \mathrm{~nm}$ but not to $337 \mathrm{~nm}$, and therefore were considered sensitive to ultraviolet stimulus. As additional single cones were absent in the cone mosaic, UV perception by central single cones or twin cones was suggested. White light and three other monochromatic stimuli elicited the retinomotor movement of all single and twin cones. These results and similar data from the literature show that the light-adaptive retinomotor movement of different spectral cone types is triggered by light perception in rods and thus do not vary by wavelength of visual stimulus between 368 and $609 \mathrm{~nm}$.

Key words: red sea bream, retina, retinomotor movement, UV sensitivity, cone type, monochromatic stimuli

In fish eyes, retinal photoreceptors and melanin pigment granules exhibit characteristic retinomotor movements in response both to ambient illumination and signals from an endogenous circadian clock. Both the light-induced and circadian-driven movements of cone myoids occur in the absence of efferent input from higher centers. ${ }^{1)}$ Circadian cone movements are regulated locally within the eye and mediated by endogenous dopamine." Color discrimination is mediated by three photoreceptor substances contained in the outer segments of the cones, each maximally sensitive to a different region of the spectrum: red, green and blue. ${ }^{2,3)}$ Some teleost fishes are known to have single cones sensitive to ultraviolet (UV) with $\lambda_{\max } 350$ to 370 nm. ${ }^{4)}$ If monochromatic stimulation brings about retinomotor movement of one cone type only and not the other, it may be possible to identify respective cones by histological examination of the retina. Many authors have investigated the mechanical responses of fish retinae to monochromatic stimuli of equal energies and determined the spectrum visible to the fishes concerned, but they have not considered the different cone types. ${ }^{5}$ The objective of this study is to examine the retinomotor movements in response to monochromatic stimuli and the UV sensitivity in the red sea bream Pagrus major. This fish is known to be color sensitive.)

\section{Materials and Methods}

Red sea bream (79-105 $\mathrm{mm}$ in total length $\mathrm{TL}$ ) were ob- tained from a local fish farmer and kept in a stock tank. Two juveniles were placed in a barrel-like glass trough measuring $12 \times 23.5 \mathrm{~cm}$, in water $16 \mathrm{~cm}$ deep. The fish were dark-adapted for at least $1 \mathrm{~h}$, and exposed to an overhead monochromatic radiation and white light for $30 \mathrm{~min}$ at water temperature $25.0-26.3^{\circ} \mathrm{C}$. The sides and bottom of the trough were covered with wrinkled aluminum foil to diffuse the radiation in the trough. Since cones respond to circadian signals, the experiment was done at night.

The light source was a stabilized DC $65 \mathrm{~V} 150 \mathrm{~W}$ xenon lamp bulb in a lamp house with a condenser lens (Irie, HXA-500), the intensity of which was varied by neutraldensity filters (Toshiba, ND). Monochromatic radiation was obtained by interposing a narrow-band monochromatic interference filter between the condenser lens and the neutral density filters. Nippon Shinku Kogaku monochromatic interference filters with peaks at 337 and $368 \mathrm{~nm}$ (UV), and Toshiba interference filters with peaks at 466 , 551 and $609 \mathrm{~nm}$ (visible light) were used. The UV intensity was measured with an UV meter (Minolta, UM-1) and visible light intensity with a photon meter (Meiwa, LICORLI-1000, sensitivity range at 400 to $800 \mathrm{~nm}$ ). The intensity of stimuli varied from $2.2 \times 10^{-4}$ to $2.3 \mu \mathrm{M} \mathrm{m}^{-2} \mathrm{~s}^{-1}$ for the visible light and from $1.3 \times 10^{-6}$ to $1.7 \times 10^{-2} \mathrm{~mW}$ $\mathrm{cm}^{-2}$ for the UV.

For histological preparation of the retinae, fish were killed by cutting the head prior to removal of both eyes. The enucleated eyes were then placed in Bouin's fixative for one day and transferred into $70 \%$ alcohol. Tissue from

\footnotetext{
*1 This study was carried out as a part of "Fundamental Study on Technical Development of Fish Behavior Control" of Marinoforum 21 Corporation.
} 
the naso-ventral retina, the area to which the overhead lights were presented, was excised and dehydrated, cleaned in xylene, and embedded in paraffin. Cross and tangential sections were cut at $6 \mu \mathrm{m}$ thick, subsequent to staining with haematoxylin and eosin.

The thickness of the pigment and cone layers provides a good measure of rates of light- and dark-adaptation and was measured with an ocular micrometer. The pigment layer was measured from the edge of the choroid to the tips of pigment protuberances. Since the cones undergo photomechanical changes in the portion of the cell proximal to the external limiting membrane, the thickness of the cone layer was measured from the membrane to the tips of the myoids. Measuring the rods was difficult due to their smallness and the masking effects of the pigment epithelial cells in the light adapted retinae. As the thickness of the layers varied with the size of the retina, each measurement was expressed as a percentage of the total retinal thickness, or retinal index. ${ }^{7)}$

In addition to the above-mentioned histological experiments, earlier preparations of retinae of juvenile red sea bream in a previous study ${ }^{8}$ were reexamined for possible changes in cone types and arrangement with growth after metamorphosis of this fish.

\section{Results}

\section{Cone Types and Arrangement}

In tangential sections of the retinae of fish smaller than $31 \mathrm{~mm} \mathrm{TL}$, single and twin cones were found to form a mosaic in a square arrangement. A central single cone was surrounded by four twin cones, with an additional single cone at a corner of the square mosaic, thus the twin cone:single cone ratio was $1: 1$. In fish $35 \mathrm{~mm} \mathrm{TL}$, the additional single cones were absent in the square mosaic and the twin cone:single cone ratio was $2: 1$. In fish (79-105 mm TL) used in the retinomotor movements, the square cone mosaic was composed also of twin cones and central single cones, with no additional single cones (Fig. 1).

\section{Retinomotor Movements in Response to Visible Light}

All eyes exposed to $466,551,609 \mathrm{~nm}$ and white light at intensities $2.2 \times 10^{-4}$ to $4.0 \times 10^{-3} \mu \mathrm{M} \mathrm{m}^{-2} \mathrm{~s}^{-1}$ were darkadapted. The cones lay close to the contracted pigment, which was in the form of a dense compact strip adjacent to the choroid. Contrary to the expectation, the monochromatic radiation induced the movement of all single and twin cones and pigment in the entire retina; all cones were completely contracted adjacent to the external limiting membrane, and pigments had migrated fully into the processes of the pigment epithelial cells almost enveloping the outer segments of the cones. The light-adaptation took place at intensities $0.02-0.042 \mu \mathrm{M} \mathrm{m}^{-2} \mathrm{~s}^{-1}$ at $466 \mathrm{~nm}, 551$ $\mathrm{nm}$ and white light and at $0.11 \mu \mathrm{M} \mathrm{m}^{-2} \mathrm{~s}^{-1}$ at $609 \mathrm{~nm}$ (Fig. 2). The cones exposed to $609 \mathrm{~nm}$ radiation migrated almost fully to the external limiting membrane at an intensity of $0.0022 \mu \mathrm{M} \mathrm{m}^{-2} \mathrm{~s}^{-1}$ whereas the cones and pigments exposed to the other wavelengths did not do so.

\section{Retinomotor Movements in Response to UV Stimuli}

The retinomotor response of the all cones and pigment was also found in the eyes exposed to $368 \mathrm{~nm} \mathrm{UV}$ at an ir-

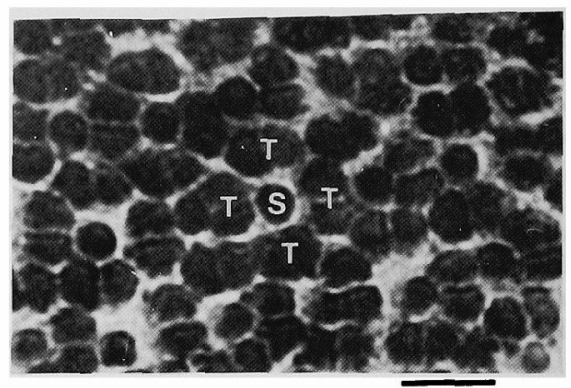

Fig. 1. Tangential section showing the square cone arrangement in the retina of a $79 \mathrm{~mm}$ TL red sea bream.

$\mathrm{T}$, twine cone; $\mathrm{S}$, central single cone. Scale bar, $20 \mu \mathrm{m}$.

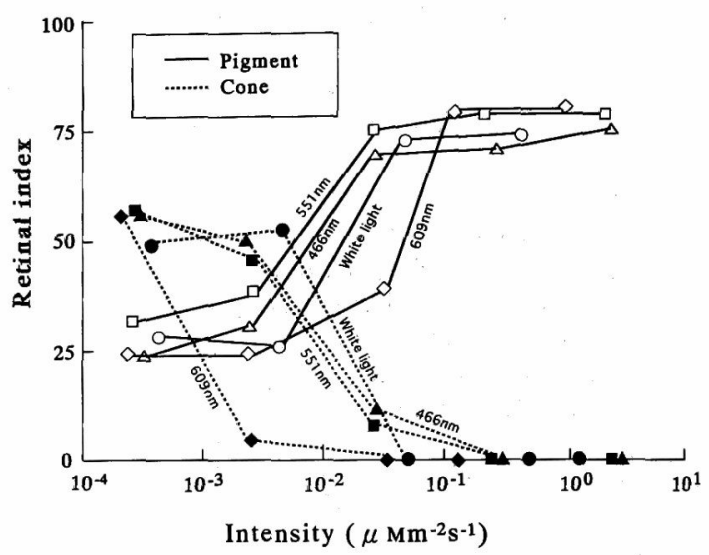

Fig. 2. Retinal index ( $\%$ of total retinal thickness) of the epithelial pigment and cone layer in the eyes of red sea bream exposed to monochromatic light and white light at various intensities.

radiance $0.046 \mathrm{~mW} \mathrm{~cm}^{-2}$ (Figs. 3A and B). Retinomotor movement was absent at $337 \mathrm{~nm} \mathrm{UV}$ at irradiance $1.3 \times 10^{-6}$ to $1.7 \times 10^{-2} \mathrm{~mW} \mathrm{~cm}^{-2}$ (Figs. $3 \mathrm{C}$ and 4 ).

\section{Discussion}

When the retina of fish exposed to a particular wavelength is light-adapted then that wavelength is visible to the fish; when the retina remains dark-adapted the fish cannot see in that light. ${ }^{7}$ ) The observed light-adaptation in response to $368 \mathrm{~nm}$ radiation indicates that this wavelength is visible to the red sea bream.

The lack of retinomotor response to $337 \mathrm{~nm}$ radiation even at an irradiance $0.016 \mathrm{~mW} \mathrm{~cm}^{-2}$, indicates poor or no sensitivity to this wavelength. UV sensitivity of fish is known to be mediated by short single cones or additional single cones. ${ }^{9-13)}$ While the additional single cones are present in the square cone mosaic of early juvenile red sea bream, ${ }^{8)}$ they disappear around $35 \mathrm{~mm}$ TL. The red sea bream used in the retinomotor movement tests had no additional single cones in the retina. However, red sea bream larger than $35 \mathrm{~mm}$ TL are still UV-sensitive. Contrary, an independent cone photoreceptor mechanism sensitive to UV is present during the early juvenile stages but is lost during normal development in brown trout Salmo trutta," Atlantic salmon $S$. salar, ${ }^{10)}$ rainbow trout Oncorhynchus mykiss, ${ }^{11)}$ rudd Scardinius erythrophthalmus, ${ }^{12)}$ and yellow perch Perca flavescens. ${ }^{13)}$ The UV sensitivity of the retina 


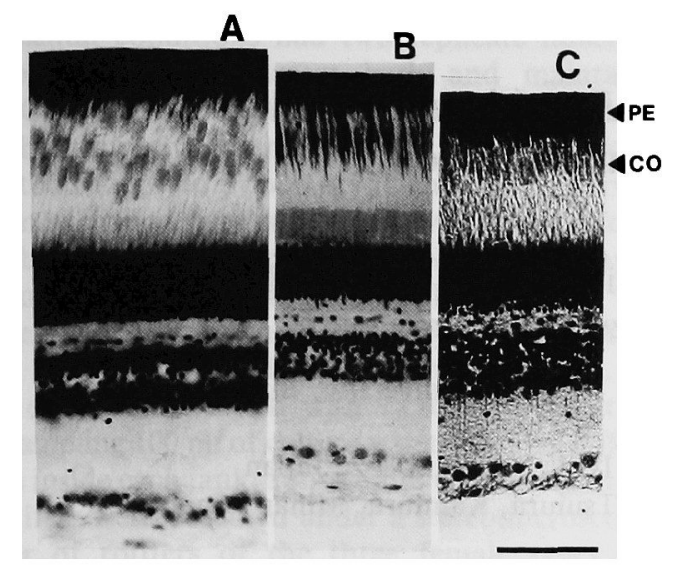

Fig. 3. Cross sections showing the retinal adaptation in UV radiation. A, Retina in the process to light-adaptation, $368 \mathrm{~nm}$ light at $4.6 \times 10^{-3} \mathrm{~mW} \mathrm{~cm}^{-2}$; B, Light-adapted retina, $368 \mathrm{~nm}$ light at $4.6 \times 10^{-2} \mathrm{~mW} \mathrm{~cm}^{-2}$; C, Dark-adapted retina, $337 \mathrm{~nm}$ light at $1.3 \times 10^{-2} \mathrm{~mW} \mathrm{~cm}^{-2}$. PE, Pigment epithelial cell layer; $\mathrm{CO}$, cone layer. Scale bar, $50 \mu \mathrm{m}$.

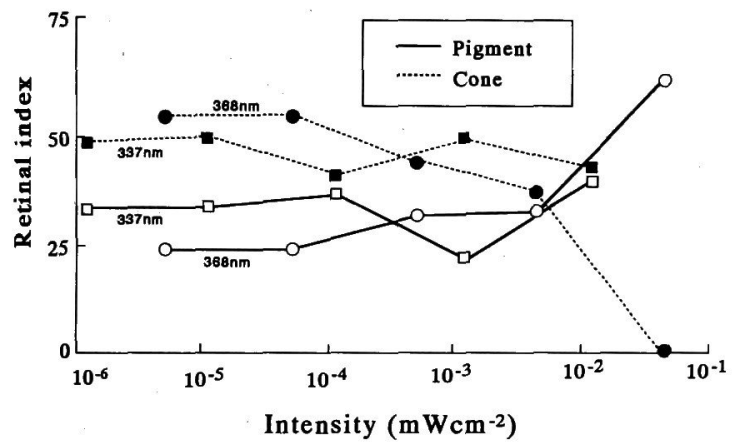

Fig. 4. Retinal index (\% of total retinal thickness) of the epithelial pigment and cone layer in the eyes of red sea bream exposed to UV radiations at various intensities.

without additional single cones in the red sea bream might indicate the mediation by central single cones or twin cones.

The cones made light-adaptive movements at a lower intensity light of $609 \mathrm{~nm}$ than any other visible light used. This result means a higher sensitivity of the cones to 609 $\mathrm{nm}$ wavelength, inconsistent with recordings of L-type Spotential from the retina of the red sea bream ${ }^{14)}$ and the general pattern in retinomotor movements in other fishes. ${ }^{5)}$ The L-type S-potential indicates a peak visual sensitivity at around $522 \mathrm{~nm}$ and low sensitivity to wavelengths longer than $612 \mathrm{~nm}$. In other fishes, the onset of migration of cones and pigments takes place at the same light intensity. The inconsistency of the present result with other findings merits further careful investigation.

In red sea bream, all cones showed light-adaptive retinomotor movement in response to monochromatic radiation at all wavelengths. $\mathrm{Ali}^{\mathrm{5})}$ speculated that the inner synaptic relationships might bring about a reaction of all cone types even when a stimulus of only one wavelength was given for an extended period. Kirsch et al. ${ }^{15)}$ electrophysiologically examined the retina of the cichlid Aequidens pulcher and concluded that light-adaptive cone contraction was triggered by light absorption in rods. In general, fishes have duplex retinae in the adult stage but pure-cone retinae in the larvae, the rods developing at metamorphosis. ${ }^{8,16,17)}$ Retinomotor movements only commence after metamorphosis when the rods develop in herring Clupea harengus, pilchard Sardina pilchardus, haddock Melanogrammus aeglefinus, and lemon sole Microstomus kitt. ${ }^{16)}$

In the red sea bream, therefore, the retinomotor response also seems to be triggered by rods. Thus all spectral cone types exhibit light-adaptive retinomotor movements in response to monochromatic radiation regardless of wavelength. This is understandable from an adaptive point of view. The offshore clean water acts as a monochromatic blue filter and the optic environment of fish offers a blue stimulus. ${ }^{18)}$ If only the blue cones react in the environment, color sensitivities would be lost even if fishes concerned are sensitive to color.

\section{References}

1) C. A. Mccormack and B. Burnside: A role for endogenous dopamine in circadian regulation of retinal cone movement. Exp. Eye Res., 55, 511-520 (1992).

2) T. Tomita, A. Kaneko, M. Murakami, and E. L. Pautler: Spectral response curves of single cones in the carp. Vision Res., 7, 519-531 (1967).

3) A. Kaneko: Physiological studies of single retinal cells and their morphological identification. Vision Res., Supl. 3, 17-26 (1971).

4) F. I. Harosi and Y. Hashimoto: Ultraviolet visual pigment in a vertebrate: A tetrachromatic cone system in the dace. Science, 207, 1021-1023 (1983).

5) M. A. Ali: Retinomotor responses. in "Vision in Fishes"' (ed. by M. A. Ali), Plenum Press, New York, 1974, pp. 313-355.

6) G. Kawamura: Recording of C-type $S$ potential from the retinae of sparidae. Nippon Suisan Gakkaishi, 47, 825 (1981).

7) M. A. Ali: Some aspects of the visual physiology of the salmon (Salmo salar). J. Mar. biol. Ass. India, 11, 255-287 (1969)

8) G. Kawamura, R. Tsuda, H. Kumai, and S. Ohashi: The visual cell morphology of Pagrus major and its adaptive changes with shift from pelagic to benthic habitats. Nippon Suisan Gakkaishi, 50, 1975-1980 (1984).

9) J. K. Bowmaker and Y. W. Kunz: Ultraviolet receptors, tetrachromatic colour vision, and retinal mosaics in the brown trout (Salmo trutta): age-dependent changes. Vision Res., 27, 2101-2108 (1987).

10) Y. W. Kunz: Tracts of putative ultraviolet receptors in the retina of the two-year-old brown trout (Salmo trutta) and the Atlantic salmon (Salmo salar). Experientia, 43, 1202-1204 (1987).

11) C. W. Hawryshn, M. G. Arnold, D. J. Chaisson, and P. C. Martin: The ontogeny of ultraviolet photosensitivity in rainbow trout (Sarmo Gairdneri). Visual Neuroscience, 2, 247-254 (1989).

12) A. V. Whitmore and J. K. Bowmaker: Seasonal variation in cone sensitivity and short-wave absorbing visual pigments in the rudd Scardinius erythrophthalmus. J. Comp. Physiol. A, 166, 103-115 (1989).

13) E. R. Loew and C. M. Wahl: A short-wavelength sensitive cone mechanism in juvenile yellow perch, Perca flavescens. Vision Res., 31, 353-360 (1991).

14) G. Kawamura, M. Hohana, T. Aramaki, and I. Shinmura: Visual recognition of HeNe-laser beam by the red sea bream. Nippon Suisan Gakkaishi, 57, 421-424 (1991) (in Japanese).

15) M. Kirsch, H. J. Wagner, and R. H. Douglas: Rods trigger light adaptive retinomotor movements in all spectral cone types of a teleost fish. Vision Res., 29, 389-396 (1989).

16) J. H. S. Blaxter: The eyes of larval fish. in "Vision in Fishes" (ed. by M. A. Ali), Plenum Press, New York, 1974, pp. 427-443.

17) G. Kawamura and N. Washiyama: Ontogenetic changes in behavior and sense organ morphogenesis in largemouth bass and Tilapia nilotica. Trans. Am. Fish. Soc., 118, 203-213 (1989).

18) N. G. Jerlov: Marine Optics, Elsevier, Amsterdam, 1976, p. 231. 